\title{
(C) OPEN ACCESS \\ Compliance with hand hygiene in emergency medical services: an international observational study
}

\author{
Heidi Storm Vikke, ${ }^{1,2}$ Svend Vittinghus, ${ }^{2}$ Matthias Giebner, ${ }_{1}^{3}$ Hans Jørn Kolmos, ${ }^{1,4}$ \\ Karen Smith, ${ }^{5,6,7}$ Maaret Castrén, ${ }^{8}$ Veronica Lindström ${ }^{9,10}$
}

Additional material is published online only. To view please visit the journal online (http://dx.doi.org/10.1136/

For numbered affiliations see end of article.

Correspondence to Dr Heidi Storm Vikke, Department of Clinical Research, hevi@falck.dk, hevi@falck.dk

Received 11 June 2018 Revised 4 December 2018 Accepted 6 December 2018 Published Online First 28 January 2019 emermed-2018-207872). University of Southern Denmark Odense 5230, Denmark:

\begin{abstract}
Introduction Healthcare-associated infection caused by insufficient hygiene is associated with mortality, economic burden, and suffering for the patient. Emergency medical service (EMS) providers encounter many patients in different surroundings and are thus at risk of posing a source of microbial transmission. Hand hygiene $(\mathrm{HH})$, a proven infection control intervention, has rarely been studied in the EMS.
\end{abstract}

Methods A multicentre prospective observational study was conducted from December 2016 to May 2017 in ambulance services from Finland, Sweden, Australia and Denmark. Two observers recorded the following parameters: $\mathrm{HH}$ compliance according to WHO guidelines (before patient contact, before clean/aseptic procedures, after risk of body fluids, after patient contact and after contact with patient surroundings). Glove use and basic parameters such as nails, hair and use of jewellery were also recorded.

Results Sixty hours of observation occurred in each country, for a total of 87 patient encounters. In total, there were 1344 indications for $\mathrm{HH}$. Use of hand rub or hand wash was observed: before patient contact, $3 \%$; before clean/aseptic procedures, 2\%; after the risk of body fluids, $8 \%$; after patient contact, 29\%; and after contact with patient-related surroundings, 38\%. Gloves were worn in 54\% of all $\mathrm{HH}$ indications. Adherence to short or up done hair, short, clean nails without polish and no jewellery was $99 \%, 84 \%$ and $62 \%$, respectively. $\mathrm{HH}$ compliance was associated with wearing gloves (OR $45 ; 95 \% \mathrm{Cl} 10.8$ to $187.8 ; p=0.000$ ) and provider level (OR 1.7; $95 \% \mathrm{Cl} 1.1$ to $2.4 ; \mathrm{p}=0.007$ ), but not associated with gender (OR $1.3 ; 95 \% \mathrm{Cl} 0.9$ to $1.9 ; p=0.107)$.

Conclusion $\mathrm{HH}$ compliance among EMS providers was remarkably low, with higher compliance after patient contacts compared with before patient contacts, and an over-reliance on gloves. We recommend further research on contextual challenges and hygiene perceptions among EMS providers to clarify future improvement strategies.

\section{Check for updates}

(C) Author(s) (or their employer(s)) 2019. Re-use permitted under CC BY-NC. No commercial re-use. See rights and permissions. Published by BMJ.

To cite: Vikke HS,

Vittinghus $\mathrm{S}$, Giebner $\mathrm{M}$,

et al. Emerg Med J

2019:36:171-175.

\section{INTRODUCTION}

Despite consistent efforts, the prevalence of healthcare-associated infection remains 5\%-10\% among patients in developed countries. These infections are associated with increased mortality, economic burden, and suffering for the patients and their families, ${ }^{1}$ thus emphasising a need to focus on prevention in everyday practice. Risk of infection is related to three key factors, the infectious agent, the host and the environment, and often the transmission of microbes takes place through direct

\section{Key messages}

What is already known on this subject

- Hand hygiene compliance is considered essential to prevent healthcare-associated infections, but very few studies have been conducted assessing compliance in the prehospital setting.

What this study adds

- This observational study conducted in Finland, Sweden, Denmark and Australia identified a suboptimal hand hygiene compliance among emergency medical service indications.

- The results suggest a tendency to selfprotection and over-reliance on gloves among emergency medical service providers ( $\leq 15 \%)$.

- The average compliance was 3\% before touching the patient and 19\% after having touched the patient. Gloves were worn in $54 \%$ of all hand hygiene indications.

or indirect contact via the hands of the healthcare provider. ${ }^{2}$ Contamination occurs during care and treatment when touching either patients or surfaces contaminated with viable pathogens from humans. The longer the duration of care and treatment, the higher the degree of contamination. Hand hygiene $(\mathrm{HH})$ is the most effective action to prevent the spread of microbes, and adherence to hygiene routines improves the quality of care and patient outcome. ${ }^{2}$ Most acute hospitalisations begin in the emergency medical services (EMS), and the providers encounter a wide range of patients in varying surrounding during single shifts, often with little or no knowledge about infection status and transmission risk. Despite these facts, hygiene in the EMS receives little attention, and most studies have focused on bioterrorism and disaster preparedness, rather than basic infection control. ${ }^{4}$ Prehospital infection control and prevention studies have focused on microbial contamination in the ambulances and on the medical equipment along with cleaning measures. However, to our knowledge, only three studies have observed $\mathrm{HH}$ compliance among EMS providers, ${ }^{4-6}$ and they do not assess $\mathrm{HH}$ compliance using multiple before and after patient parameters, nor are their results based on data from multiple countries.

The aim of our study was to provide an assessment of $\mathrm{HH}$ compliance, glove behaviour and adherence to basic hygiene parameters regarding 
hair, nails and the use of jewellery among EMS providers across multiple countries and professions. We also wanted to investigate potential risk factors related to lack of $\mathrm{HH}$ compliance.

\section{METHODS}

\section{Design and setting}

We conducted a prospective observational study including EMS providers from Finland, Sweden, Denmark and Australia from December 2016 to May 2017. All included countries have written hygiene guidelines, but the degree of implementation is unknown. Two observers each did 30 hours of non-participating observation (6 hours a day, during the daytime, on weekdays, in one pre-determined week) in each of the four countries. The participants were either defined as basic-care providers or advanced-care providers and employed by either a public or a private EMS organisation. The annual number of patient cases across participating cities ranged from approximately 60000 to 400000.

\section{Inclusion/exclusion}

Enrolment was conducted from a convenience sample of EMS providers that were on duty on the preplanned data collection days. Only front-line personnel from ground vehicles was included. The participants were informed about hygiene being the overall subject of observation, but not that $\mathrm{HH}$ was the exact focus.

\section{Data collection}

The observers looked at three areas: hand hygiene, glove behaviour and basic hygiene parameters. Observations were conducted on five $\mathrm{HH}$ indications, according to the WHO 'Your five moments for hand hygiene' validated scheme ${ }^{78}$ (figure 1). Observers were instructed that if two indications occurred continuously (eg, when going from an after contact to a before aseptic procedure), this was considered as only one indication for $\mathrm{HH}$.

Hand rub and hand wash procedures were defined using the WHO definitions: 'hand rub' is applying an antiseptic hand rub to reduce or inhibit the growth of micro-organisms, and 'hand

\section{Before patient contact: occurs between the last hand-to-surface contact and the first patient contact. E.g., after touching something in the ambulance environment and before touching the patient.}

Before a clean or aseptic procedure: occurs between the last hand-to-surface contact, and instantly before an aseptic or clean procedure. E.g., before establishing a venous access line, giving an injection or performing wound care.

After risk of body fluid exposure: occurs after contact before touching any surfaces. E.g., after handling a wound or being in contact with mucosa.

After patient contact: occurs after any contact with the patient. E.g., after touching the patient.

After contact with patient surroundings: occurs after touching the immediate surroundings of the patient, even if there is no actual contact with the patient. E.g., after handling the patient belongings, the stretcher harness, etc.

Figure 1 Five moments for hand hygiene according to WHO recommendations. $^{78}$ wash' is washing hands with plain or antimicrobial soap and water. ${ }^{7}$ Use of gloves is only recommended if there is a reasonable risk of contact with blood or other potentially infectious materials, mucous membranes or non-intact skin. ${ }^{7}$ Assessment of glove behaviour had three outcome possibilities: when new gloves were put on, if one pair of gloves were used continually through more than one $\mathrm{HH}$ indication or if no gloves were used. Adherence to basic hygiene parameters was visually assessed by recording compliance to recommendations on short clean nails (no visible soil, and white tips $<3 \mathrm{~mm}$ long), no use of nail polish (bare nails), having short or up done hair (no longer than to the chin/neck), and no use of rings and watches ${ }^{9}{ }^{10}$ (see online supplementary appendix 1 and 2 for Australian and Finnish guidelines, respectively). Finally, gender and provider level were recorded.

\section{Statistics}

Data were initially recorded on paper and then entered directly into STATA 14 for analysis. To prevent entry errors, each variable was evaluated in relation to predefined expected values by running the STATA codebook command. The primary outcome was $\mathrm{HH}$ compliance. Secondary outcomes were differences between countries, and associations between $\mathrm{HH}$, gender and provider level, and between $\mathrm{HH}$ and glove use. Descriptive analyses of all variables were conducted overall and by country, and the results presented by frequencies and percentages. Country comparison and assessment of the association between $\mathrm{HH}$ compliance, glove behaviour, gender and provider level were conducted using $\chi^{2}$ tests if the expected frequency were above 5. If the expected frequency were below 5, Fisher's exact test was used.

Additionally, we performed univariate and multivariate analyses to assess whether provider level, gender and use of gloves could be regarded as potential risks factors related to lack of $\mathrm{HH}$ compliance using logistic regression. We corrected for interaction in the multivariate model if any association was detected. In all analyses, Alpha was 0.05 .

\section{RESULTS}

\section{General characteristics}

During 240 hours, 77 EMS providers were observed, 87 patient cases completed and $1344 \mathrm{HH}$ indications recorded (71 individual providers, as two from Finland and four from Sweden were observed twice because of their work schedule). Table 1 shows that provider level, gender and observed indications varied significantly by country.

\section{Hand hygiene compliance}

Hand rub was the preferred $\mathrm{HH}$ action as hand washes only were observed seven times (all after patient contact). The overall $\mathrm{HH}$ compliance was $15 \%$ regardless of $\mathrm{HH}$ indication, but when analysing the data per indication, we found a compliance rate of $3 \%$ before patient contact, $2 \%$ before clean or aseptic procedures, $8 \%$ after the risk of contact with body fluids, 29\% after patient contact and 38\% after contact with patient surroundings. The compliance rate varied significantly according to the country of origin. The Danish providers had the highest compliance rate regardless of indication (table 2 ).

\section{Glove behaviour}

In total, the use of gloves was observed in 720 (54\%) of all 1344 indications. New gloves were observed in $48 \%$ of all before patient contacts, but only in $14 \%$ of all clean or aseptic 
Table 1 General characteristics per observed hand hygiene indication, overall and by country

\begin{tabular}{|c|c|c|c|c|c|c|}
\hline \multirow[b]{2}{*}{$N=1344$} & Overall & Finland & Sweden & Denmark & Australia & \multirow[b]{2}{*}{$P$ value } \\
\hline & \multicolumn{5}{|l|}{ n (\%) } & \\
\hline \multicolumn{7}{|l|}{ Provider level } \\
\hline Basic care & $349(26)$ & $39(16)$ & $174(42)$ & $136(32)$ & 0 & \multirow[t]{2}{*}{0.000} \\
\hline Advanced care & $995(74)$ & $198(84)$ & $244(58)$ & $289(68)$ & $264(100)$ & \\
\hline \multicolumn{7}{|l|}{ Gender } \\
\hline Male & $852(63)$ & $149(63)$ & $195(47)$ & 405 (95) & $103(39)$ & \multirow[t]{2}{*}{0.000} \\
\hline Female & $492(37)$ & $88(37)$ & $223(53)$ & $20(5)$ & $161(61)$ & \\
\hline \multicolumn{7}{|l|}{ Hand hygiene indications } \\
\hline Before patient & $513(38)$ & $77(32)$ & $156(37)$ & $182(43)$ & $98(37)$ & \multirow[t]{5}{*}{0.002} \\
\hline Before clean/aseptic & $158(12)$ & $43(18)$ & $53(13)$ & $27(6)$ & $35(13)$ & \\
\hline After body fluids & $119(9)$ & $23(10)$ & $41(10)$ & $31(7)$ & $24(9)$ & \\
\hline After patient & $482(36)$ & $76(32)$ & $148(35)$ & $165(39)$ & $93(35)$ & \\
\hline After surroundings & $72(5)$ & $18(8)$ & $20(5)$ & $20(5)$ & $14(6)$ & \\
\hline
\end{tabular}

procedures. Continuous use of gloves (wearing a pair of gloves through more than one $\mathrm{HH}$ indication, for example, after touching a contaminated site, and then returning to the patient) was observed in $21 \%$ of the before patient contacts, and in $64 \%$ of the observed before clean or aseptic procedures. Moreover, the use of gloves varied significantly by country (table 3 ).

\section{Adherence to basic hygiene parameters}

The adherence to basic hygiene parameters regarding nails, hair and jewellery among the EMS providers was higher than the $\mathrm{HH}$ compliance. In total, $83 \%$ of the EMS providers had short, clean nails, 99\% had short or up done hair, and 62\% did not wear jewellery. Furthermore, the adherence by country did not vary significantly, except regarding wearing jewellery (table 4).

\section{Influence of gender and provider level on HH compliance and glove behaviour}

$\mathrm{HH}$ compliance did not vary by gender (16\% men vs $13 \%$ women, $\mathrm{p}=0.175$ ), but by provider level (basic-care providers $21 \%$ vs advanced-care providers $12 \%, \mathrm{p}=0.000)$. Wearing gloves did not vary by gender (male providers $53 \%$ vs female providers $55 \%$, $\mathrm{p}=0.399$ ), but it did vary by provider level (basic-care providers $42 \%$ vs advanced-care providers $57 \%, \mathrm{p}=0.000)$.

\section{Potential risk factors related to lack of $\mathrm{HH}$ compliance}

$\mathrm{HH}$ compliance was observed in $2 \%$ of the 720 indications where gloves were worn, whereas it was observed in $30 \%$ of the 624 indications where no gloves were worn $(p=0.000)$.

In multivariate analysis, non-compliance with $\mathrm{HH}$ was associated with wearing gloves (OR 45; 95\% CI 10.8 to $187.8 ; \mathrm{p}=0.000$ ) and with provider level (OR 1.7; 95\% CI 1.1 to $2.4 ; \mathrm{p}=0.007)$, but not with gender (OR 1.3; 95\% CI 0.9 to $1.9 ; \mathrm{p}=0.107$ ) (table 5).

\section{DISCUSSION}

We found a low $\mathrm{HH}$ compliance rate both in general and on a country level. The behaviour of the EMS providers showed a tendency towards self-protection instead of patient protection, that is, with a higher compliance rate after patient contacts than before patient contacts and with an over-reliance on gloves. We observed the use of gloves when there was no apparent need (no observed risk of body fluids, etc). There was also a high rate of continuous use of the same pair of gloves throughout several $\mathrm{HH}$ indications. The adherence to hygiene parameters regarding hair, nails and the use of jewellery was better with an overall adherence rate from $62 \%$ to $99 \%$, depending on the parameter. Moreover, the risk of non-compliance was related to glove use and provider level.

This multicentre study is the first to assess $\mathrm{HH}$ compliance in accordance with WHO recommendations, along with adherence to recommendations regarding hair, nails and jewellery among various EMS professions across multiple countries, and thus providing a broader assessment than seen before. However, this also makes it difficult to compare our results with prior findings.

To the best of our knowledge, only three HH-related observational studies have been conducted in the EMS setting (two American and one Swedish), and these studies also found $\mathrm{HH}$ compliance among EMS providers to be suboptimal with a tendency to self-protection. ${ }^{5} 611$ The issue of self-protection has two aspects, both the greater $\mathrm{HH}$ compliance after patient contact and the over-reliance of gloves, and therefore it is important to note that $\mathrm{HH}$ is about preventing the spread of microbes and thus protecting the patient. Whereas, the use of gloves primarily is about protecting oneself from body fluids, and so on.

The WHO 'Five moments for hand hygiene' may be challenging to comply fully with in demanding clinical practices, and they may need some simplification to be feasible in the EMS.

Table 2 Hand hygiene compliance in general and per indication, overall and per country

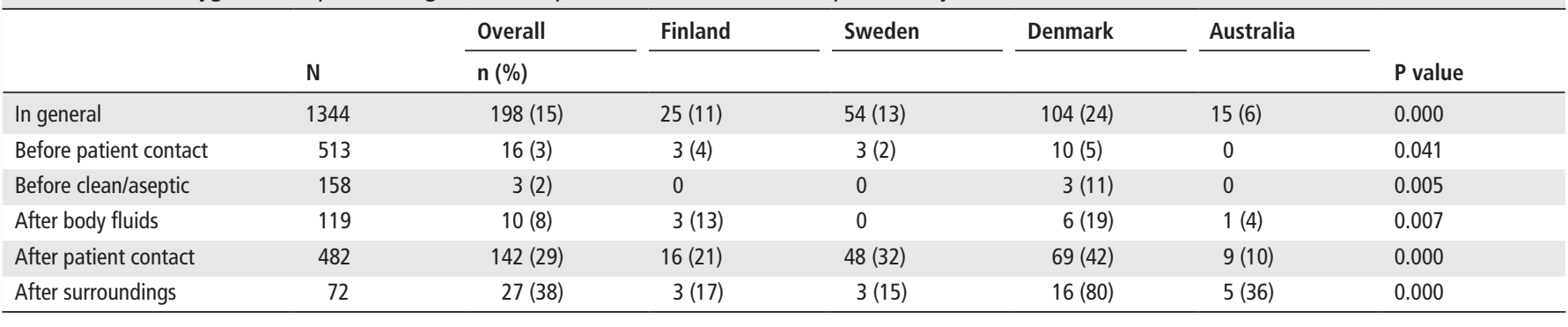


Table 3 Glove behaviour among emergency medical service providers, overall and per country

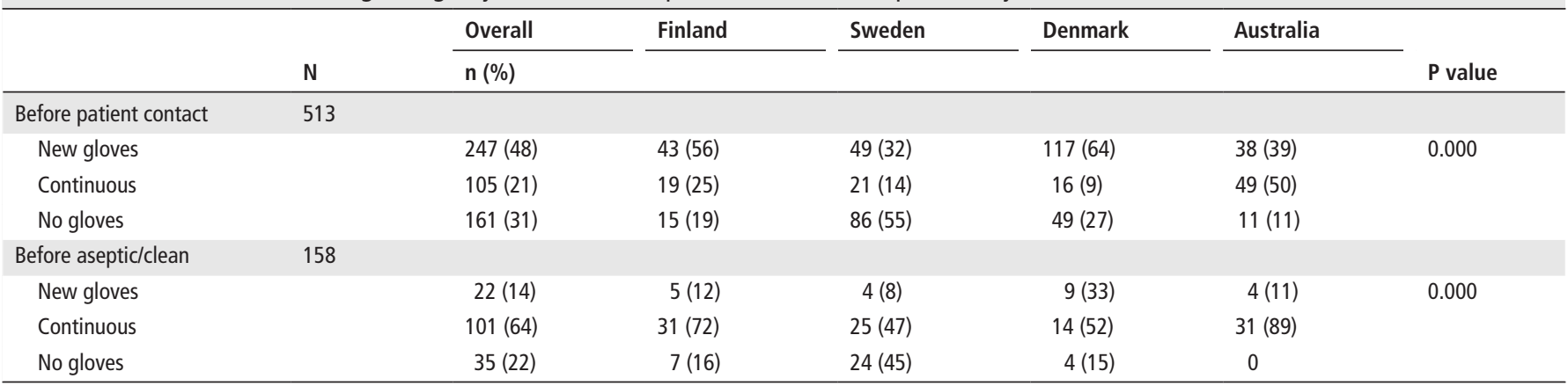

Also, it is important to remember that although $\mathrm{HH}$ is not a complicated procedure, it still needs to be learnt, trained and continually practised before it becomes a routine.

The move towards more advanced and invasive procedures being performed in the EMS setting underpins the need for improvement strategies because poor $\mathrm{HH}$ is related to a heavy load of bacteria on the hands, ${ }^{4}$ and provides a risk of transmission and subsequently risk of infection. ${ }^{12} 13$

We found a poor $\mathrm{HH}$ compliance both overall and in each of the enrolled countries, and thus potential improvement strategies should be discussed. One challenge to $\mathrm{HH}$ compliance in the EMS setting is lack of access to supplies at the point of care. ${ }^{11}$ Access to running water and soap is often restricted to the ED, and hand rub is often only available in the ambulance. A potential solution to such a challenge is to accept the use of presoaked wipes suitable for skin hygiene as an alternative to hand wash and to hand out pocket-sized hand rub bottles to the EMS providers.

Despite WHO's recommendations specifying that $\mathrm{HH}$ should be performed before putting on gloves and after removal of gloves, ${ }^{7}$ the amount of $\mathrm{HH}$ actions we observed did not match the use of gloves. A possible explanation could be that gloves are regarded as a substitute for $\mathrm{HH}$ by the EMS providers as reported elsewhere. ${ }^{14}$ It could also be that wearing gloves preclude $\mathrm{HH}$ actions, ${ }^{11} 15$ which is in line with the association between non-compliance and wearing gloves we found in the present study. However, further investigation of these presumptions is needed.

The fact that we found a lower $\mathrm{HH}$ compliance among the advanced-care providers could be interpreted as a cause of their higher competencies and thus more profound patient contact with a substantial workload, resulting in sparse attention towards HH. Such an interpretation is supported by a recent study on hygiene perceptions among EMS providers, which suggest that they perceive $\mathrm{HH}$ as time consuming and compromising their patient interactions. ${ }^{14}$ Similar challenges in regard to $\mathrm{HH}$ compliance among doctors, nursing assistants and so on have been reported elsewhere. ${ }^{2}$

The different $\mathrm{HH}$ compliance rates found in the enrolled countries in our study is especially interesting in relation to future improvement strategies. All four countries had written hygiene guidelines, and all providers were educated within the field of emergency care and treatment, and thus should be equally informed about the nature and necessity of hygiene. However, the Danish EMS had been accredited a few years ago. ${ }^{16}$ This accreditation process brought focus on several clinical parameters, including hygiene, which may have resulted in the significantly higher $\mathrm{HH}$ compliance in Denmark. However, we are unable to investigate the potential cause-effect relation in the present study.

Insufficient training, time pressure and limited access to hygiene supplies have been reported as challenges related to EMS HH compliance. ${ }^{46141718}$ WHO recommends a multimodal approach to $\mathrm{HH}$ compliance, and such will imply a variety of strategies in order to clarify both practical and behavioural barriers. ${ }^{7}$ As far as we know, only one study has investigated how to improve EMS-related $\mathrm{HH}$, and the authors reported that a theoretically based PowerPoint presentation on $\mathrm{HH}$ importance and practice, along with increased access to $\mathrm{HH}$ supplies, and visually reminding posters, improved the hygiene awareness and motivation. ${ }^{18}$ Also, a recent Australian study reported that situation-based learning had a positive impact on medical students' knowledge and attitudes towards $\mathrm{HH} .{ }^{19}$ Future studies elucidating motivational factors in relation to EMS $\mathrm{HH}$ compliance are highly recommended to strengthen future multimodal improvement strategies.

\section{Strengths and limitations of the study}

The fact that our data collection, as the first ever, was conducted across different countries, including both private and public organisations and multiple EMS professions, contributes to the study generalisability. However, although statistically significant results have been attained in some areas, the numbers reported are reasonably low, and thus country-specific interpretation should be made with caution.

Observation of $\mathrm{HH}$ compliance is considered the gold standard', ${ }^{20}$ but one must assume that our study design is challenged by the observer influence known as the 'Hawthorne effect', where the observed tend to increase their effort to 'please' the observer, and there is no doubt that the EMS providers were under some influence of the observers. Nevertheless, it should be considered

Table 4 Emergency medical service providers' adherence to hygiene parameters regarding nails, hair and jewellery, overall and per country

\begin{tabular}{|c|c|c|c|c|c|c|}
\hline & Overall & Finland & Sweden & Denmark & Australia & \multirow[b]{2}{*}{$P$ value } \\
\hline & n (\%) & & & & & \\
\hline Clean short nails & $64(83)$ & $15(75)$ & $19(95)$ & $18(90)$ & $12(71)$ & 0.153 \\
\hline Short/up done hair & 76 (99) & $20(100)$ & $19(95)$ & $20(100)$ & $17(100)$ & 1.000 \\
\hline No jewellery & $48(62)$ & $9(45)$ & $14(70)$ & $20(100)$ & $5(29)$ & 0.000 \\
\hline
\end{tabular}


Table 5 Risk factors related to lack of hand hygiene* compliance among emergency medical service providers

\begin{tabular}{|c|c|c|c|c|c|c|c|}
\hline \multirow[b]{2}{*}{ Potential risk factors } & \multirow{2}{*}{$\begin{array}{l}\text { Observed number } \\
\text { of non-compliances }\end{array}$} & \multicolumn{3}{|c|}{ Univariate analysis } & \multicolumn{3}{|c|}{ Multivariate analysis $t$} \\
\hline & & $\mathrm{OR}$ & $95 \% \mathrm{Cl}$ & $P$ value & OR & $95 \% \mathrm{Cl}$ & $P$ value \\
\hline Advanced-care level & $872 / 1146$ & 1.9 & 1.4 to 2.7 & 0.000 & 1.7 & 1.1 to 2.4 & 0.007 \\
\hline Female & $428 / 1146$ & 1.2 & 0.9 to 1.7 & 0.176 & 1.3 & 0.9 to 1.9 & 0.107 \\
\hline Wearing gloves & $708 / 1146$ & 25.0 & 14 to 45 & 0.000 & 45.0 & 10.8 to 187.8 & 0.000 \\
\hline
\end{tabular}

*Either hand wash or hand rub.

tIncluding an interaction term between 'wearing gloves and educational level' (interaction non-significant, $\mathrm{p}=0.309$ ).

a strength that the EMS providers were unaware of the precise observational focus and that they were informed about data being anonymised before being analysed. Also, both observers did their best to blend in and limit their appearance as much as possible. Moreover, the two observers collected the data in all four countries, and thus the interobserver variation should be limited. ${ }^{20}$ The chosen WHO validated data collection scheme is considered suitable for all healthcare settings, ${ }^{7}$ but not commonly used in the EMS.

\section{CONCLUSION}

$\mathrm{HH}$ compliance among EMS providers was remarkably low and higher after patient encounters compared with before patient encounters. In addition, there was an over-reliance on gloves, indicating a tendency towards self-protection instead of patient protection. We recommend further research on contextual challenges and hygiene perceptions among EMS providers to clarify future improvement strategies.

\section{Author affiliations}

Department of Clinical Research, University of Southern Denmark, Odense, Denmark ${ }^{2}$ Medical Office, Falck Danmark A/S, Kolding, Denmark

${ }^{3}$ A \& E Department, Sygehus Soenderjylland, Aabenraa, Denmark

${ }^{4}$ Department of Clinical Microbiology, Odense University Hospital, Odense, Denmark

${ }^{5}$ Centre fro Research and Evaluation, Ambulance Victoria, Melbourne, Victoria,

Australia

${ }^{6}$ Department of Community Emergency Health and Paramedic Practice, Monash

University, Melbourne, Victoria, Australia

${ }^{7}$ Department of Epidemiology and Preventive Medicine, Monash University, Melbourne, Australia

${ }^{8}$ Department of Emergency Medicine and Services, Helsinki University Hospital, Helsinki University, Helsinki, Finland

${ }^{9}$ Department of Neurobiology, Care Sciences and Society, Division of Nursing, Karolinska Institutet, Stockholm, Sweden

${ }^{10}$ SamordnareAkademisk ambulans SLL, Academic EMS, Stockholm, Sweden

Acknowledgements A big thank you to Falck Emergency in Denmark and Sweden, EMS of the Peijas district in Uusimaa, Finland and Ambulance Victoria in Australia. Without their effort and interest, this study would not have been possible.

Contributors HSV wrote the protocol under supervision from MG, HJK, KS, MC and VL. The planning and execution of data collection were conducted by HSV and SV with support from MC, KS and VL. All statistics were conducted by HSV under the supervision of HJK. Writing the article was done by HSV under the supervision of MG, HJK, KS, MC and VL. All authors read and approved the final manuscript.

Funding Falck Denmark A/S and the Danish Innovation fund co-funded the study in a Business PhD partnership.

Competing interests None declared.

Patient consent Not required.

Ethics approval All study phases were conducted under strict consideration of the Declaration of Helsinki. Participation was voluntary and all observations anonymised. In Denmark, the study was exempted from specific ethical approval due to the noninterventional nature of the study. Ethical approval in Finland, Sweden and Australia was obtained according to local regulations and local human research ethics committees. All observations prioritised the well-being of the patients.

Provenance and peer review Not commissioned; externally peer reviewed.
Data sharing statement The datasets generated and analysed during the current study are not publicly available due to commercial interests but are available from the corresponding author on reasonable request.

Open access This is an open access article distributed in accordance with the Creative Commons Attribution Non Commercial (CC BY-NC 4.0) license, which permits others to distribute, remix, adapt, build upon this work non-commercially, and license their derivative works on different terms, provided the original work is properly cited, appropriate credit is given, any changes made indicated, and the use is non-commercial. See: http://creativecommons.org/licenses/by-nc/4.0/.

\section{REFERENCES}

1 World Health Organization (WHO). Report on the Burden of Endemic Health CareAssociated Infection Worldwide A systematic review of the literature. 2011 (accessed 5 Jun 2018).

2 Allegranzi B, Pittet D. Role of hand hygiene in healthcare-associated infection prevention. J Hosp Infect 2009;73:305-15.

3 Kolmos HJ. Health care-associated infections: sources and routes of transmission: INTECH Open Access Publisher, 2012.

4 Teter J, Millin MG, Bissell R. Hand hygiene in emergency medical services. Prehosp Emerg Care 2015;19:313-9.

5 Emanuelsson L, Karlsson L, Castrèn M, et al. Ambulance personnel adherence to hygiene routines: still protecting ourselves but not the patient. Eur J Emerg Med 2013;20:281-5.

6 Ho JD, Ansari RK, Page D. Hand sanitization rates in an urban emergency medical services system. J Emerg Med 2014;47:163-8.

7 World Health Organization (WHO). Guidelines on Hand Hygiene in Health Care: A Summary. 2009 http://www.who.int/gpsc/information_centre/hand-hygienesummary/en/ (accessed 5 Jun 2018).

8 Sax H, Allegranzi B, Uçkay I, et al. 'My five moments for hand hygiene': a user-centred design approach to understand, train, monitor and report hand hygiene. J Hosp Infect 2007:67:9-21.

9 Statens Serum Institut (SSI). Nationale Infektionshygiejniske Retningslinjer. 2016. Available at https://www.ssi.dk/Smitteberedskab/Infektionshygiejne/Retningslinjer/ NIR.aspx (accessed 5 Jun 2018).

10 Stockholm County. Medicinske behandlingsriktlinjer. 2017. Available at http://www. aisab.nu/media/49863/2015_medicinska_behandlingsriktlinjer.pdf (accessed 5 Jun 2018).

11 Bledsoe BE, Sweeney RJ, Berkeley RP, et al. EMS provider compliance with infection control recommendations is suboptimal. Prehosp Emerg Care 2014;18:290-4.

12 Johansson M, Phuong DM, Walther SM, et al. Need for improved antimicrobial and infection control stewardship in Vietnamese intensive care units. Trop Med Int Health 2011;16:737-43.

13 Mathur P. Hand hygiene: back to the basics of infection control. Indian J Med Res 2011:134:611-20.

14 Barr N, Holmes M, Roiko A, et al. Self-reported behaviors and perceptions of Australian paramedics in relation to hand hygiene and gloving practices in paramedic led health care. Am J Infect Control 2017;45:771-8.

15 Talon $\mathrm{D}$. The role of the hospital environment in the epidemiology of multi-resistant bacteria. J Hosp Infect 1999:43:13-17.

16 The Danish Institute for Quality and Accreditation in Healthcare (IKAS). Introduction to DDKM. Available at https://www.ikas.dk (accessed 5 Jun 2018).

17 Bucher J, Donovan C, Ohman-Strickland P, et al. Hand washing practices among emergency medical services providers. West J Emerg Med 2015;16:727-35.

18 McGuire-Wolfe C, Haiduven D, Hitchcock CD. A multifaceted pilot program to promote hand hygiene at a suburban fire department. Am J Infect Control 2012;40:324-7.

19 Kaur R, Razee H, Seale H. Setting the right foundations: improving the approach used to teach concepts of hand hygiene to medical students. J Hosp Infect 2017;95:355-8.

20 Sax H, Allegranzi B, Chraïti MN, et al. The World Health Organization hand hygiene observation method. Am J Infect Control 2009;37:827-34.

21 The World Medical Association, INC. Declaration Of Helsinki, Ethical Principles for Medical Research Involving Human Subjects. https://www.wma.net/wp-content/ uploads/2016/11/DoH-Oct2008.pdf (Accessed 30 May 2015). 